\title{
On exchange rates and efficiency ${ }^{\star}$
}

\author{
Eric O'N. Fisher \\ Department of Economics, The Ohio State University, Columbus, OH 43210, USA
}

\begin{abstract}
Summary. This paper analyzes an exchange economy in which several assets serve as stores of value and where agents have completely heterogeneous preferences and endowments. It describes the set of perfect foresight equilibria in which all assets have positive prices. There are international policies with determinate exchange rates if the world economy satisfies a strong efficiency criterion. Also, the corresponding equilibrium allocations are in the core of the world economy for certain international policies. Hence, a system of fixed exchange rates can support efficient allocations to the extent that countries agree on a division of seigniorage in the creation of international reserves.
\end{abstract}

\section{Introduction}

One of the most celebrated results in the theory of international finance is that the equilibrium exchange rate is indeterminate in models of overlapping generations with several assets. Using a stationary model, Kareken and Wallace [19] showed that for any exchange rate there was a unique equilibrium in which all currencies and goods traded freely and that each exchange rate had real effects. ${ }^{1}$ The purpose of this paper is to develop this insight more deeply; using Malinvaud's [21] strong criterion, we explore the relationship between exchange rates and the efficiency of equilibrium allocations in a wide class of economies.

Most analyses of dynamic efficiency focus on a sequence of homogeneous agents, but economies with one representative agent per generation miss the essence of international economics: trade between countries. Of course, allocations are efficient if and only if: (i) there is no feasible reallocation among the agents of any one

\footnotetext{
* I would like to thank an annonymous referee, Suchan Chae, Mike Woodford, Ken Kasa, Helen Popper, Kathryn Marshall, and seminar participants at the University of Kansas, the Federal Reserve board, the 1990 meetings of the Western Economic Association, the University of Western Ontario, the University of Chicago, the University of Pennsylvania, Purdue University, and Victoria University of Wellington for comments on earlier drafts.

1 Kareken and Wallace restrict their attention to what Gale [16] calls Samuelsonian equilibria; hence, their result is not as general as has been widely believed.
} 
generation that makes one person better off without hurting any other; and (ii) there is no such feasible reallocation between the agents of different generations.

The primary contribution of this paper is that, for certain configurations of country-specific generational deficits, considerations of economic efficiency eliminate the generic multiplicity of exchange rates. By imposing a strong efficiency criterion, we show that one vector of exchange rates suffices for dynamic efficiency when countries run disparate generational deficits. A surprising implication of this analysis is that some exchange rates support allocations that are in the core of the world economy. Thus my analysis gives the first rigorous theoretical justification of Mundell's [22] classic observation about a system of fixed exchange rates, and I show why it is in the interest of one government to sacrifice its own policy independence. Moreover, the efficiency criterion I analyze can be tested empirically by checking whether countries in a system of fixed exchange rates have stocks of national (generational) debt whose present values are co-integrated.

Here is the intuition. Consider a world economy with a fixed stream of endowments and a given profile of national generational deficits. Different exchange rates give rise to different real values of generational deficits and real interest rates. Not every such profile supports an efficient consumption path. As we shall see below, exchange rates that divide the seigniorage from the creation of international reserves help ensure the dynamic efficiency of the world economy.

The model here is based upon that developed in Fisher [14], which is in turn an extension of the model developed by Balasko and Shell [5] and [6]. Agents have completely heterogeneous endowments and preferences; hence, agents differ across countries as well as through time. There are no restrictions on trade in goods or assets at any time. To the best of my knowledge, this is the most general model of overlapping generations that has been used in international finance. ${ }^{2}$

The rest of this paper is structured as follows. The next section describes the model. The third section characterizes equilibria with international generational policies, and the fourth describes aspects of the relationship between exchange rates and economic efficiency. The fifth section gives two examples of international economies where determinate exchange rates divide the gains from trade, and the sixth section presents my conclusions and an agenda for future empirical research.

\section{The model}

I extend the fundamental papers of Balasko and Shell [5] and [6] by assuming that there are several agents in each generation, with each agent living for two periods. ${ }^{3}$ The agents alive at the beginning of the economy live for only one period. Groods

\footnotetext{
2 There has been almost no literature on dynamic efficiency in international economics, although Buiter [9] is a notable exception. Still, most research using overlapping generations in international economics has been accomplished with diagrammatic analysis or with analytical solutions to simple difference equations. Hence, it has concentrated exclusively on stationary economies.

3 The fact that these agents live for only two periods is not as restrictive as it seems. Balasko, Cass, and Shell [4] give an algorithm for transforming an arbitrary model of overlapping generations into the one we use here by a labeling convention on dated commodities. Benveniste [8] is careful to explain that this algorithm has implications for how one might define the inter-temporal efficiency condition.
} 
cannot be stored, and at least two fiat assets serve as a store of value. Agents have heterogeneous preferences and endowments, and $\ell$ goods are available in each period. Each agent has smooth, convex, and monotone preferences, and the closure of her indifference surfaces are contained in the positive orthant of $\ell$-dimensional or $2 \ell$-dimensional Euclidean space. Further, each agent is endowed with strictly positive amounts of every good in each period of her life, and she may receive taxes or transfers from different fiscal authorities. ${ }^{4}$

The set of people born at time $t$ is $G_{t}$, and $N_{t}=\# G_{t}<\infty$. Then

$$
G=\bigcup_{t=0}^{\infty} G_{t}
$$

is the index set of agent in the world economy. A list of countries is a partition of this set. There are $m \geq 2$ different countries, each with its own fiat asset. Let $\mathscr{G}=\left\{G^{1}, \ldots, G^{m}\right\}$ partition $G$; then agent $h \in G^{j}$ is a resident of the $j$-th (and only the $j$-th) country. The set agents alive at time $t$ is $G_{t} \cup G_{t-1}$, and $h \in G^{j} \cap G_{t}$ is a resident of country $j$ born at time $t$. Although the world population may vary from period to period, there is always an agent trading with another person who will survive her. I will call the $m$ fiscal authorities governments.

It will be convenient to represent commodity bundles, prices, and government policies as sequences. The allocation of agent $h \in G_{t}$ is

$$
x_{h}=\left(0, \ldots, x_{h}^{t}, x_{h}^{t+1}, 0, \ldots\right),
$$

where $x_{h}^{t, i}$ is her allocation of good $i$ at time $t$ and $x_{h}^{t} \in \mathbb{R}_{+}^{t}$. Likewise, her endowment is

$$
\omega_{h}=\left(0, \ldots, \omega_{h}^{t}, \omega_{h}^{t+1}, 0, \ldots\right),
$$

with $\omega_{h}^{t} \in \mathbb{R}_{++}^{\ell}$. So the space of commodity bundles is

$$
X=\mathbb{R}_{+}^{N_{0} \ell} \times \mathbb{R}_{+}^{2 N_{1} \ell} \times \mathbb{R}_{+}^{2 N_{2} \ell} \times \ldots,
$$

and the list of endowments for the world economy is $\omega=\left(\omega_{h}\right)_{h \in G} \in X$. Note that I am using the index set of agents here.

Since there is more than one country, the description of lump-sum transfers is more complicated than the usual case. Let $m_{h}^{t, j}$ be agent $h$ 's receipts of fiat asset $j$ at time $t$; if $m_{h}^{t, j}<0$, then agent $h$ is taxed in asset $j$ at time $t$. For $h \in G_{0}$, let $m_{h}^{1}=\left(m_{h}^{1,1}, \ldots, m_{h}^{1, m}\right) \in \mathbb{R}^{m}$, where the $j$-th element of this vector denotes receipts at time 1 of type-j assets. For any $h \in G \backslash G_{0}$, such transfers are $\left(m_{h}^{t}, m_{b}^{t+1}\right) \in \mathbb{R}^{2 m}$. Again,

$$
m_{h}=\left(0, \ldots, m_{h}^{t}, m_{h}^{t+1}, 0, \ldots\right) \text {. }
$$

An international policy is the full list $m=\left(m_{h}\right)_{h \in G^{*}}$. Note that we are considering policies that give all types of assets to all kinds of people.

The agents in the world economy can create as many inside assets of any denomination as they may please. Let $y_{h}^{t, j}$ be the gross additions at time $t$ to the type- $j$ assets of $h \in G_{t}$, with $y_{h}^{t} \in \mathbb{R}^{* x}$ the corresponding vector. I impose that $y_{h}^{1} \geq 0$ for $h \in G_{0}$

\footnotetext{
4 These assumptions are sufficient to ensure the existence of an equilibrium without fiat assets in the discussion below.
} 
and $y_{h}^{t}+y_{h}^{t+1} \geq 0$ for $h \in G \backslash G_{0}$. These vector-valued inequalities state that no one can die a net debtor in any asset and no one holds assets when she is not alive. Again

$$
y_{h}=\left(0, \ldots, y_{h}^{t} y_{h}^{t+1}, 0, \ldots\right)
$$

represents the incremental asset holdings of agent $h \in G_{r}$.

I consider the set of perfectly foreseen present value commodity prices with the normalization $p^{1,1}=1$. A sequence of goods prices is

$$
p=\left(p^{1}, p^{2}, \ldots\right)
$$

where $p^{t} \in \mathbb{R}_{++}^{\ell}$ and $p \in \mathscr{P}$, the set of present-value prices. Then $p^{1, \mathrm{i}} / p^{t, i}$ is commodity $i$ 's own rate of interest between periods 1 and $t$. Let $q^{t, j}>0$ be the price of type-j assets at time $t$, and let $q^{t} \in \mathbb{R}_{++}^{m}$ be the vector of all $m$ such prices. ${ }^{5}$ The sequence of such prices is

$$
q=\left(q^{1}, q^{2}, \ldots\right)
$$

and $q \in \mathscr{Q}$, the set of present-value asset prices. Since the price of each asset is strictly positive, any bilateral exchange rate is well defined. Moreover, asset prices are not otherwise restricted because no further normalization is warranted without loss of generality in the analysis below.

Agent $h \in G \backslash G_{0}$ has utility function $u_{h}: \mathbb{R}_{+}^{2 \ell} \rightarrow \mathbb{R}$ and maximizes: ${ }^{6}$

$$
\begin{gathered}
u_{h}\left(x_{h}^{t}, x_{h}^{t+1}\right) \\
\text { subject to } \\
p \cdot x_{h}+q \cdot y_{h} \leq p \cdot \omega_{h}+q \cdot m_{h} \equiv w_{h}, \\
x_{h} \geq 0, \text { and } y_{h}^{t}+y_{h}^{t+1} \geq 0,{ }^{7}
\end{gathered}
$$

where $w_{h}$ is the present value of her wealth, including the taxes and transfers that accrue during the course of her life. All of these inner products are well defined because only finitely many elements of $x_{h}, y_{h}, \omega_{h}$, and $m_{h}$ are not zero.

Define the aggregate supply of type- $j$ assets in period $t$ as:

$$
M^{t, j}=\sum_{s=1}^{t} \sum_{h \in G_{s} \cup G_{s-1}} m_{h}^{s, j}
$$

where $m_{h}^{s, j} \in \mathbb{R}$. Further, write $M^{t} \in \mathbb{R}^{m}$ as the vector of asset supplies at time $t$, and let $M=\left(M^{1}, M^{2}, \ldots\right)$. Also, let the sequence

$$
Y_{h}=\left(0, \ldots, 0, y_{h}^{t} y_{h}^{t}+y_{h}^{t+1}, 0, \ldots\right)
$$

describe the cumulative asset holdings of agent $h$.

The following concept is useful.

\footnotetext{
${ }^{5}$ The restriction that each asset price is strictly positive is quite important. It entails that each country's policy plays a non-trivial role in determining the equilibrium allocations in the world economy.

${ }^{6}$ Agent $h \in G_{0}$ has a utility function $u_{h}: \mathbb{P}_{+}^{\ell} \rightarrow \mathbb{R}$.

7 The problem for $h \in G_{0}$ is analogous, and we impose that $y_{h}^{0} \equiv 0 \in \mathbb{R}^{m}$.
} 
Definition 1: A perfect foresight equilibrium with valued fiat assets is a list of goods prices $p \in \mathscr{P}$, asset prices $q \in \mathscr{Q}$, allocations $x \equiv\left(x_{h}\right)_{h \in G}$, and cumulative asset holdings $Y \equiv\left(Y_{h}\right)_{h \in G}$ such that: (i) $x_{h}$ solves (1); (ii) $\sum_{h \in G} x_{h} \leq \sum_{h \in G} \omega_{h}$; and (iii) $\sum_{h \in G} Y_{h} \leq M$.

Condition (ii) describes material balances; it is an infinite-dimensional vectorinequality stating that aggregate demand for each dated commodity not exceed aggregate supply. Condition (iii) describes equilibrium in asset markets; it too is an infinite-dimensional inequality describing the demand for the stocks of assets and their supplies.

We now state our first proposition.

Proposition 1: Consider a world economy associated with $\omega \in X$ and international policy $m \in M$. Let $p \in \mathscr{P}$ be a sequence of good prices in a perfect foresight equilibrium with valued fiat assets. Then the present prices of the fiat assets satisfy $q=\left(q^{0}, q^{0}, \ldots\right)$, where $q^{0} \in \mathbb{R}_{++}^{m}$. Hence, in such an equilibrium, all bilateral exchange rates are constant.

Proof: The fact that all present value asset prices are constant follows from Balasko and Shell [6, Proposition 3.1]. Note that the exchange rate of currency $k$ in terms of currency $j$ is $e^{t, k, j}=q^{t, k} / q^{t, j}$. Since $q^{t, j}>0$ for all $t$ and $j$, the Proposition follows.

Proposition 1 states that each nominal exchange rate is constant; this is an implication of a perfect foresight equilibrium. The normalization that $p^{1,1}=1$ entails that the present value of an exchange rate is constant; hence, uncovered interest parity holds. ${ }^{8}$ Proposition 1 does not imply that real exchange rates are constant. The definition of a real exchange rate in a model this general would entail a price index of traded and not-traded goods for each of the different countries. ${ }^{9}$ Only by a fluke would such an index be constant for any one country.

Proposition 1 defines $m(m-1)$ bilateral exchange rates. Since $q^{0, j} / q^{0, k} \equiv$ $e^{j, k}=1 / e^{k, j}$, not all of these exchange rates are independent. Indeed, using arguments involving triangular arbitrage, one can show that only $m-1$ of these exchange rates are independent. We have set up a rich enough structure to analyze the central theoretical issue of this paper.

\section{Equilibria with international generational policies}

In this section, we shall show how equilibrium in the goods market depends upon the generational policies adopted by all countries. The intuition is that a government increases the purchasing power of those to whom it gives lump-sum transfers, as long as its expansion is not so egregious as to destroy the value of its fiat asset.

Let $p \in \mathscr{P}$, and recall that the present value of agent $h$ 's wealth is:

$$
w_{h}=p \cdot \omega_{h}+q \cdot m_{h}
$$

\footnotetext{
${ }^{8}$ Since this model admits inside assets, there is no difference between uncovered and covered interest parity in a perfect foresight equilibrium.

${ }^{9}$ Let dated commodity $(t, i)$ be a not-traded good in country $j$. Then condition (ii) of Definition 1 is necessary but not sufficient for equilibrium. It would have to be replaced with: $\sum_{h \in G^{j}} x_{h}^{t, i} \leq \sum_{h \in G^{j}} \omega_{h}^{t, i}$ for each such dated commodity.
} 
Again, these expressions are well defined because only finitely many elements of $\omega_{h}$ and $m_{h}$ are not-zero. Since asset prices are constants, the present value of $h$ 's wealth depends only upon the sum of transfers that he receives. It is convenient to define:

$$
\mu_{h}^{j}= \begin{cases}m_{h}^{1, j} & \text { if } h \in G_{0} \\ m_{h}^{t, j}+m_{h}^{t+1, j} & \text { if } h \in G \backslash G_{0} .\end{cases}
$$

Of course, $\mu_{h} \in \mathbb{R}^{m}$ is the vector of transfers accruing to agent $h$. Let $\mu^{j}=\left(\mu_{h}^{j}\right)_{h \in G}$ be the generational policy of countryj. ${ }^{10}$ The conventional measure of a government deficit is derived from $\left(m^{t, j}, m^{t+1, j}\right)_{h \in G}$, but the real effect of government $j$ 's policy is determined by $\mu^{j}=\left(\mu_{h}^{j}\right)_{h \in G}$. An international generational policy is a list of $m$ different sequence $\mu=\left\{\mu^{1}, \ldots, \mu^{m}\right\}$. Let $\mathscr{M}$ be the set of such policies. These policies are general enough so that countries may tax or subsidize every $h \in G .^{11}$

Now let $\mathscr{S}=\{(p, q) \mid p \in \mathscr{P}$ and $q \in \mathscr{Q}\}$, and recall $q^{t}=q^{t+1}=q^{0}$ in a perfect foresight equilibrium. The demand of $h$ at time $t$ is a function $f_{h}^{t}: \mathscr{P} \times \mathbb{R}_{+} \rightarrow \mathbb{R}_{+}^{t}$, derived as the solution to (1) for a given $p \in \mathscr{P}$ and $w_{h}=p \cdot \omega_{h}+q^{0} \cdot \mu_{h} \in \mathbb{R}_{+}$. Then

$$
f_{h}\left(p, w_{h}\right)=\left(0, \ldots, f_{h}^{t}\left(p, w_{h}\right), f_{h}^{t+1}\left(p, w_{h}\right), 0, \ldots\right)
$$

describes $h$ 's demands. The material balances condition is:

$$
\sum_{h \in G} f_{h}\left(p, w_{h}\right) \leq \sum_{h \in G} \omega_{h}
$$

This vector inequality is infinite-dimensional, and each of its elements is well defined because only finitely many of the elements of $f_{h}\left(p, w_{h}\right)$ and $\omega_{h}$ are not zero and $N_{t}=\# G_{t}$ is finite for all $t$.

Now let $\mathscr{S}(\omega, \mu)$ denote the set of perfect foresight equilibrium prices supporting some equilibrium consistent with the endowments $\omega \in X$ and international generational policy $\mu \in \mathscr{M}$. Further, let

$$
r=\left(r^{1}, r^{2}, \ldots\right)=\sum_{h \in \boldsymbol{G}} \omega_{h}
$$

be the stream of resources in the world economy. Consider a list of incomes $w=\left(w_{h}\right)_{h \in G}$ and $p \in \mathscr{P}$. Then we can define the following useful concept:

Definition 2: The sequence $(p, w)$ is a price-income equilibrium associated with world resources $r$ if and only if $\sum_{h \in G} f_{h}\left(p, w_{h}\right)=r$. For $\omega \in X$, the international generational policy $\mu \in \mathscr{M}$ is consistent with the price-income equilibrium $(p, w)$ if and only if there is a $q^{0} \in \mathbb{R}_{++}^{m}$ such that $w_{h}=p \cdot \omega_{h}+q^{0} \cdot \mu_{h}$ for $h \in G$.

\footnotetext{
${ }^{10}$ This is the terminology of Auerbach, Gokhale, and Kotlikoff [2]. It is important for both theoretical and empirical reasons. By now it is well known that the conventional government deficit is not well defined. Moreover, any econometric test based on the Theorems below must recognize that generational, not conventional, deficits determine the dynamic efficiency of the equilibrium allocations in the world economy.

11 Consider $m_{h}^{t, j}>0$ where $h \in G_{t} \cap G^{k}$. This subsidy appears on country j's current account as a unilateral transfer to abroad, and its present value is $q^{0, j} m_{h}^{t, j}$. In practice, these transfers can be quite substantial. Net unilateral transfers of the United States were more than ten percent of the external deficit in recent years.
} 
Define $\Lambda^{t} \equiv \sum_{s=0}^{t} \sum_{h \in G_{s}} \mu_{h}$, (roughly) the vector of liquidity that has been injected until time $t$. The present value of this liquidity is $q^{0} \cdot A^{t}$. The following proposition characterizes the international generational policies that are consistent with a given price-income equilibrium.

Proposition 2: The international generational policy $\mu \in \mathscr{M}$ is consistent with the price-income equilibrium $(p, w)$ if and only if:

$$
-p^{t+1} \cdot\left(\sum_{h \in G_{t+1}} f_{h}^{t+1}\left(p, w_{h}\right)\right)<q^{0} \cdot A^{t}<p^{t+1} \cdot\left(\sum_{h \in G_{t}} f_{h}^{t+1}\left(p, w_{h}\right)\right) .
$$

Proof: This is an implication of Fisher [14, Proposition 6]; the argument is a simple extension of Balasko and Shell [6, Proposition 5.5].

I am actually interested in describing the properties of $\mathscr{S}(\omega, \mu)$, but it is not at all easy to determine whether this set is empty in a model this general. That is why we use the concept of a price-income equilibrium. If $\mu=0$ trivially, then there is enough structure on this economy to show that there is an equilibrium. Since no agent's wealth is affected by the prices of the different assets for any $q^{0} \in \mathbb{R}_{++}^{m}$, $(p, q) \in \mathscr{S}(\omega, \mu) \neq \varnothing$. In general, it is not possible to describe $\mathscr{S}(\omega, \mu)$ explicitly; instead, we show below that special generational policies $\mu \in \mathscr{M}$ are consistent with a price-income equilibria $(p, w)$ whose allocations are efficient. Then we explore the circumstances under which one vector of exchange rates suffices to guarantee the efficiency of these allocations.

\section{Equilibrium exchange rates}

Consider the world economy $(\omega, \mu)$ and assume that $\mathscr{S}(\omega, \mu) \neq \varnothing$. Let $Q^{0}(\omega, \mu) \subseteq \mathbb{R}_{++}^{m}$ be the set of all asset prices giving rise to some $(p, q) \in \mathscr{S}(\omega, \mu)$. $Q^{0}(\omega, \mu)$ is not empty because $\mathscr{S}(\omega, \mu) \neq \varnothing$. We are interested in the dimension of $Q^{\circ}(\omega, \mu)$; if $\operatorname{dim} Q(\omega, \mu)>1$, then there are several vectors of the $m-1$ independent exchange rates that are consistent with some perfect foresight competitive equilibrium. Kareken and Wallace have already shown that the exchange rate is indeterminate for the Samuelsonian equilibria in one class of stationary economies.

Let $q^{0} \in Q^{\circ}(\omega, \mu)$. Then it is easy to recover the $m-1$ independent exchange rates by the function $g: Q^{0} \rightarrow\{1\} \times \mathbb{R}_{++}^{m}$, whose rule is:

$$
g\left(q^{0}\right)=\left(1, q^{0,2} / q^{0,1}, \ldots, q^{0, m} / q^{0,1}\right) .
$$

We are particularly interested in whether $Q^{0}(\omega, \mu)$ is contained in a one-dimensional linear sub-space of $R_{++}^{m}$, in which case the exchange rates in the world economy are determinate.

Even though the equilibrium exchange rates are constant, the vector of exchange rates influences equilibrium allocations in two ways. First, exchange rates have effects on the distribution of consumption within each generation. Second, they re-allocate consumption between generations.

We state now a proposition concerning the first effect.

Proposition 3: Assume that $\mathscr{S}(\omega, \mu) \neq \varnothing$. If the elements of $\mu$ are not linearly independent, then $\operatorname{dim} \mathscr{Q}^{\circ}(\omega, \mu)>1$. 
Proof: Let $(p, q) \in \mathscr{S}(\omega, \mu) \neq \varnothing$. Consider the corresponding price-income equilibrium $(p, w)$, with $w_{h}=p \cdot \omega_{h}+q^{0} \cdot \mu_{h}$. Since the elements of $\mu$ are not linearly independent, there is some $m \times 1$ vector $\alpha \neq 0$ such that $\alpha \cdot \mu_{h}=0$ for all $h \in G$. But then

$$
w_{h}=p \cdot \omega_{h}+q^{0} \cdot \mu_{h}=p \cdot \omega_{h}+\left(q^{0}+\alpha\right) \cdot \mu_{h}=p \cdot \omega_{h}+\left(q^{0}+\lambda \alpha\right) \cdot \mu_{h}
$$

for some $\lambda>0$. Since $q^{0} \in \mathbb{R}_{++}^{m}$, there is a continuum of $\lambda>0$ such that $\left(q^{0}+\lambda \alpha\right) \in \mathbb{R}_{+}^{m}$ and $q^{0}+\lambda \alpha$ is consistent with $(p, w)$. Hence, $\operatorname{dim} Q^{0}(\omega, \mu)>1$.

Consider an economy with red and blue assets. Each agent receives a tax or transfer imposed in strict proportions of one red note and one blue note. Since $p^{1,1}=1$, the numérarire might well be a pound of sterling silver at time $1(1699$, say, when Sir Isaac Newton became master of the mint). Then it does not matter if the red note is worth three pounds sterling and the blue note seven or if both notes are worth five pounds sterling. The exchange rate is entirely indeterminate since $\operatorname{dim} Q^{\circ}(\omega, \mu)=2$.

When will the elements of $\mu$ be linearly independent? One common assumption in international economics is that each agent receives transfers in only one currency. Then the elements of $\mu$ are certainly linearly independent and exchange rates affect the distribution of resources within each generation. Another possibility is a representative-agent model with disparate patterns of currency transfers. Then exchange rates influence the rate of increase of asset balances in the world economy.

In exploring inter-temporal efficiency in the rest of this paper, we will impose

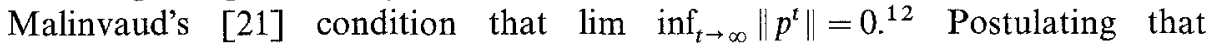
$\liminf _{t \rightarrow \infty}\left\|p^{t}\right\|=0$ entails that every commodity's own-rate of interest is eventually positive. If world resources are uniformly bounded, then interest rates are greater than the long-run growth rate of the world economy. We now state our first important result.

Theorem 1: Assume that there is a uniform bound on world resources. Let $\liminf _{t \rightarrow \infty} \Lambda^{t}=\Lambda$. If $(p, q) \in \mathscr{S}(\omega, \mu) \neq \varnothing$ satisfies $\liminf _{t \rightarrow \infty}\left\|p^{t}\right\|=0$, then the $m-1$ exchange rates satisfy $\left[g\left(q^{0}\right)\right] \cdot \Lambda=0$.

Proof: Let $r$ be the stream of world resources, and let $K$ be a uniform upper bound on $\left\|r^{t}\right\|$. Since $\mathscr{S}(\omega, \mu)$ is not empty, $Q^{0}(\omega, \mu)$ is also not empty, and there is a price-income $(p, w)$ equilibrium satisfying $(3)$. Then the goods market equilibrium implies that:

$$
\begin{aligned}
\left|q^{0} \cdot \Lambda^{t}\right|<\max & \left\{\left\|p^{t} \cdot\left[\sum_{h \in G_{t-1}} f_{h}^{t}\left(p, w_{h}\right)\right]\right\|,\left\|p^{t} \cdot\left[\sum_{h \in G_{t}} f_{h}^{t}\left(p, w_{h}\right)\right]\right\|\right\} \\
& \leq\left\|p^{t} \cdot r^{t}\right\| \leq\left\|r^{t}\right\|\left\|p^{t}\right\| \leq K\left\|p^{t}\right\| .
\end{aligned}
$$

Since $\liminf \operatorname{in}_{t \rightarrow \infty}\left\|p^{t}\right\|=0, \liminf _{t \rightarrow \infty}\left|q^{0} \cdot \Lambda^{t}\right|=0$. Since $Q^{0}(\omega, \mu)$ is not empty, $q^{0,1}>0$. Hence, $\left(q^{0} / q^{0,1}\right) \cdot \Lambda=0$.

${ }^{12}$ Here $\left\|p^{t}\right\|$ denotes the Euclidean norm of the vector $p^{t}$. In order to describe necessary and sufficient conditions for efficiency, one must impose further assumptions about the curvature of the economy's feasible sets, as in Cass [10] and Benveniste [8], or about that of consumers' indifference surfaces, as in Balasko and Shell [5]. 
If $(p, q) \in S(\omega, \mu)$ satisfies $\liminf \operatorname{si\infty }_{t}\left\|p^{t}\right\|=0$, then the world economy is in what Gale [16] called the "classical case" and the present value of the stock of the world generational debt is retired asymptotically. ${ }^{13}$ It is important to emphasize that these kinds of equilibria do permit positive stocks of generational debt in each period in the world economy, although some agent must be taxed eventually in order to amortize the international generational debt. Thus, if $\Lambda \neq 0 \in \mathbb{R}^{m,}$, Theorem $1 \mathrm{im}-$ poses a linear restriction on the set of asset prices $\mathscr{2}^{\circ}(\omega, \mu)$. It does not state that $Q^{0}(\omega, \mu)$ lies in a one-dimensional sub-space of $\mathbb{R}_{++}^{m}$, but dynamic efficiency implies that exchange rates lie in a linear sub-space of $\mathbb{P}_{++}^{m}$, whose dimension is no greater than $m-2$. Hence exchange rates are not entirely indeterminate.

The next concept illustrates some interesting implications of Theorem 1.

Definition 3: $\mu^{j}$ is frequently balanced if and only if $\liminf _{t \rightarrow \infty} \Lambda^{t, j}=0$.

This is akin to the terminology of Balasko and Shell [7]. If a generational policy is not frequently balanced, then a country's debt or surplus is permanent. The beauty of a model with $m \geq 2$ assets is that there may be several elements of $\mu$, none of which is frequently balanced, and yet $\lim \inf _{i \rightarrow \infty}\left[g\left(q^{0}\right)\right] \cdot A^{t}=0$.

We state:

Corollary 1.1: Consider a world with two countries. Assume that there is a uniform bound on world resources and that $(p, q) \in \mathscr{S}(\omega, \mu) \neq \varnothing$ satisfies $\liminf _{t \rightarrow \infty}\left\|p^{t}\right\|=0$. Then: (i) if $\liminf _{t \rightarrow \infty} \Lambda^{t, 1}>0$, then $\lim \inf _{t \rightarrow \infty} \Lambda^{t, 2}<0$; and (ii) if $\lim _{t \rightarrow \infty} \Lambda^{t, 1} \neq 0$ and $\lim _{t \rightarrow \infty} \Lambda^{t, 2}$ exists, then the exchange rate is unique.

Proof: To show (i), let $\liminf _{t \rightarrow \infty} \Lambda^{t, 1}=\Lambda^{1}$ and let $\Lambda^{2}$ be analogous. Since $\mathscr{S}(\omega, \mu) \neq \varnothing$, there is a $q^{0} \in \mathbb{R}_{++}^{2}$ satisfying (3). Theorem 1 implies that $\left(\Lambda^{t, 2}\right)_{t=0}^{\infty}$ has an accumulation point $\Lambda^{2}$ such that $q^{0,1} \Lambda^{1}+q^{0,2} \Lambda^{2}=0$; hence, $\Lambda^{2}<0$. To establish (ii), let $\lim _{t \rightarrow \infty} \Lambda^{t, 1}=\Lambda^{1} \neq 0$. Note that $\lim _{t \rightarrow \infty} \Lambda^{t, 2}=\Lambda^{2} \neq 0$ because both $q^{0,1}$ and $q^{0,2}$ are strictly positive and $q^{0,1} \Lambda^{1}+q^{0,2} \Lambda^{2}=0$. Hence, $e^{2,1}=-\Lambda^{1} / \Lambda^{2}$.

Assume that there is a perfect foresight equilibrium that supports efficient allocations. If one government conducts an expansionary generational policy, then the other must conduct a contractionary one, and the exchange rate is determinate. ${ }^{14}$ The latter government keeps asset balances within appropriate bounds for world economy. This argument has the flavor of Mundell's classic redundancy argument [22]; one fiscal authority "sacrifices" its independence in order to keep the equilibrium allocations of all agents in the world economy efficient. In a system of fixed exchange rates, one country must run generational surpluses if some country runs a policy that is not frequently balanced.

\footnotetext{
${ }^{13}$ Esteban and Millán [13] use the analogous terminology that the equilibrium allocations are in the "classical set."

14 The expansionary country runs generational deficits, while the other country runs analogous surpluses. Building on the work of Auerbach and Kotlikoff [3], Fisher [15] shows that the conventiona] current account surplus is not well defined and then defines the aggregate generational curtent account surplus. There is strong evidence that countries run trade surpluses whose present value is not stationary over very long horizons. Such a phenomenon cannot be explained by models with infinitely lived agents when the usual transversality conditions are imposed.
} 
It is important to emphasize the intuition behind Corollary 1.1. An expansionary government creates too great an asymptotic supply of asset balances. If the other government did not "lean against the wind," then the equilibrium would not be efficient. Since there is free trade in all goods and assets, it is inappropriate to conclude that there is too much of any one asset; the problem is that there is too much of all types of assets unless another government corrects this imbalance.

Following Chae and Esteban [12], we define another helpful concept. A coalition is a non-empty subset $S \subseteq G$, the index set of agents. An assignment is a list of consumption bundles $x=\left(x_{h}\right)_{h \in G}$, which may or may not be feasible. Then, for any coalition $S$ and assignment $x \in X$,

$$
\begin{aligned}
F_{S}(x)= & \left\{v \in X: \sum_{h \in S} z_{h}=v \text { for some assignment } z\right. \text { such that } \\
& \left.u_{h}\left(z_{h}\right) \geq u_{h}\left(x_{h}\right) \text { for all } h \in S \text { and } u_{h}\left(z_{h}\right)>u_{h}\left(x_{h}\right) \text { for some } h \in S\right\}
\end{aligned}
$$

denotes the set of resources that can be distributed among the members of $S$ such that no member of $S$ is worse off and at least one member of $S$ is strictly better off than is the case under the assignment $x$. Recall that $\omega_{h}$ is the endowment of agent $h$. We now state:

Definition 4: An feasible allocation $x$ belongs to the core if $\sum_{h \in S} \omega_{h} \notin F_{s}(x)$ for any coalition $S$.

Of course, an allocation $x \in X$ is in the core if it cannot be improved upon by any coalition. ${ }^{15}$ In the examples given below, we show that there are equilibria where countries run trade surpluses in order to maintain access to international capital markets. Even though there is imbalanced trade, the equilibrium allocations in the world economy Pareto-dominate autarky.

In fully dynamic international economies, there are two natural coalitions that might arise. The first is the set of agents in a generation, and the second is the full sequence of agents constituting a country. This observation allows us to state a deep concomitant of Theorem 1.

Corollary 1.2: Let $\ell=1$, and assume that there is a uniform bound on world resources. Consider $(p, q) \in \mathscr{S}(\omega, \mu)$. If the equilibrium allocations are in the core, then the $m-1$ exchange rates satisfy $\left[g\left(q^{0}\right)\right] \cdot \Lambda=0$.

Proof: (By contradiction) Assume that $\left[g\left(q^{0}\right)\right] \cdot \Lambda \neq 0$. Then Theorem 1 implies that there is a period $T$ and an $\varepsilon>0$ such that, for all $t \geq T, p^{t} \geq \varepsilon$. Equilibrium in the goods market for period $t \geq T$ entails that

$$
p^{t+1}\left[\sum_{h \in G_{t}} x_{h}^{t+1}-\sum_{h \in G_{t}} \omega_{h}^{t+1}\right]=q^{0} \cdot \Lambda^{t},
$$

where $x=\left(x_{h}\right)_{h \in G}$ are the equilibrium allocations.

15 Hendricks, Judd, and Kovenock [17] gave the first example of Walrasian equilibrium allocations not in the (empty) core in a model of overlapping generations. Kovenock [20] showed that there are Pareto-optimal Walrasian equilibrium allocations not in the (empty) core. Esteban and Millán [13] showed that there are Pareto-optimal Walrasian equilibrium allocations in an economy whose core is not empty. 
If $q^{0} \cdot \Lambda^{t}>0$, then for sufficiently large $t$

$$
\sum_{h \in G_{t+1}} \omega_{h}^{t+1}-\sum_{h \in G_{t+1}} x_{h}^{t+1} \geq q^{0} \cdot \Lambda^{t} / \varepsilon \equiv \delta_{1}>0 .
$$

Consider the coalition $S=\cup_{s=t+1}^{\infty} G_{s}$ and assignment

$$
z_{h}= \begin{cases}x_{h} & \text { if } h \in G_{t+1} \text { and } x_{h}^{t+1} \geq \omega_{h}^{t+1} \\ \left(0, \ldots, x_{h}^{t+1}+\delta_{1} / \# G_{t+1}, x_{h}^{t+2}, 0, \ldots\right) & \text { if } h \in G_{t+1} \text { and } x_{h}^{t+1}<\omega_{h}^{t+1}\end{cases}
$$

and $z_{h}=x_{h}$ if $h \in S \backslash G_{t+1}$. Note that $\sum_{h=S} z_{h} \leq \sum_{h \in S} \omega_{h}$ and that $u_{h}\left(z_{h}\right) \geq u_{h}\left(x_{h}\right)$ for all $h \in S$, with at least one strict inequality. Hence, $\left(x_{h}\right)_{h \in G}$ is not in the core.

If $q^{0} \cdot \Lambda^{t}<0$, then for sufficiently large $t$

$$
\sum_{h \in G_{t}} x_{h}^{t+1}-\sum_{h \in G_{t}} \omega_{h}^{t+1} \leq q^{0} \cdot \Lambda^{t} / \varepsilon \equiv \delta_{2}<0 .
$$

Now consider the coalition $S=\bigcup_{s=0}^{t} G_{s}$ and assignment

$$
z_{h}= \begin{cases}x_{h} & \text { if } h \in G_{t} \text { and } x_{h}^{t+1} \geq \omega_{h}^{t+1} \\ \left(0, \ldots, x_{h}^{t}, x_{h}^{t+1}+\delta_{2} / \# G_{t}, 0, \ldots\right) & \text { if } h \in G_{t} \text { and } x_{h}^{t+1}<\omega_{h}^{t+1}\end{cases}
$$

and $z_{h}=x_{h}$ if $h \in S \backslash G_{t^{\prime}}$. Again, $\sum_{h \in S} z_{h} \leq \sum_{h \in S} \omega_{h}, u_{h}\left(z_{h}\right) \geq u_{h}\left(x_{h}\right)$ for all $h \in S$, with at least one strict inequality, and thus $\left(x_{h}\right)_{h \in G}$ is not in the core.

The assumption that there is one good per period places this result firmly within the literature on aggregative economics. Consider now a world economy with a non-empty core. Assume that one country creates such a large asymptotic supply of its asset that the equilibrium allocations are not Pareto efficient. Then the countries in the world economy could agree on a different array of generational policies enhancing the distributive efficiency of the world economy. Such an agreement would be self-enforcing because the vector of exchange rates and the new policy support equilibrium allocations in the core of the world economy.

There are world economies in which countries are willing to run generational surpluses in order to maintain access to international capital markets. This fact is at the essence of why a country would "sacrifice its policy independence" and run an external surplus. A surplus country maintains the dynamic efficiency of the world economy because access to the international trading system allows for a Pareto improvement over the allocations that it could achieve without international financial markets!

Much of the literature on the core in a model of overlapping generations has been concerned with convergence of the core to the set of Walrasian equilibrium allocations. Chae [11] and Aliprantis and Burkinshaw [1] are two important examples. But most important theoretical issues in international economics arise precisely because countries are atoms. Hence, in natural applications in international economics, the core of the world economy may be much larger than the set of competitive equilibrium allocations. This insight will be exploited in the examples below.

If the stream of world resources is uniformly bounded, the Malinvaud criterion implies that $\left(q^{0} \cdot \Lambda^{t}\right)_{t=0}^{\infty}$ has an accumulation point at zero. If there were only one asset in this model, then $\mu$ would have to be frequently balanced. Since there are 
$m \geq 2$ assets, there may be several elements of $\mu$ that do not have this property, but there may be linear combinations of these sequences that do. The reader familiar with time-series econometrics will see that the vector of asset prices serves as a co-integrating vector for the $m$-dimensional deterministic process $\left(\Lambda^{t}\right)_{t=0}^{\infty}$. This allows us to state a surprising result.

Theorem 2: Assume that $\mathscr{S}(\omega, \mu) \neq \varnothing$ and that there is a uniform bound on world resources. If each $(p, q) \in \mathscr{S}(\omega, \mu)$ satisfies $\liminf _{t \rightarrow \infty}\left\|p^{t}\right\|=0$, then the dimension of $Q^{0}(\omega, \mu)$ is given by the number of co-integrating vectors of $\left(\Lambda^{t}\right)_{t=0}^{\infty}$.

Proof: Since $\mathscr{S}(\omega, \mu)$ is not empty, $Q^{0}(\omega, \mu)$ is also not empty. For each $q^{0} \in Q^{0}(\omega, \mu)$, there is a price-income $(p, w)$ equilibrium satisfying (3). Theorem 1 then implies that there is a subsequence of $\left(\Lambda^{t}\right)_{t=0}^{\infty}$ having an accumulation point at zero. Let $\left\{\alpha_{i}\right\}_{i=1}^{r}$, with $r \leq m$, be linearly independent $m \times 1$ vectors that span $Q^{0}(\omega, \mu)$.

Now let $A$ be the $m \times r$ matrix whose $i$-th column is $\alpha_{i}$. Consider a subsequence such that $\lim _{k \rightarrow \infty} A^{\prime} \Lambda^{t_{k}}=0$. The columns of $A$ are the co-integrating vectors of the process $\left(\Lambda^{t_{k}}\right)_{k=1}^{\infty}$. Since $Q^{0}(\omega, \mu)$ lies in the column space of $A, \operatorname{dim} Q^{0}(\omega, \mu)=r$.

If $\operatorname{dim} Q^{0}(\omega, \mu)=r<m$, the series $\left(\Lambda^{t}\right)_{t=0}^{\infty}$ has $m-r$ common trends, to use the apt terminology of Stock and Watson [23]. In Corollary 1.1, there is only one common trend in that two-dimensional process. This trend is the pattern of adjustment to the incipient asset market disequilibrium caused by the expansion inherent in one country's generational policy (or the contraction inherent in its trading partner's policy). Two examples in the next section provide deeper insight into these common trends.

\section{Applications}

The first example describes a world economy consisting of two countries with identical preferences but different endowments. International trade benefits benefits both countries, and there is a unique exchange rate that divides the gains from trade between the two countries.

Example 1: Let $m=2$ and $N_{t}=\# G_{t}=2$ for all $t \geq 0$. Since $m=N_{t}$, we can identify sequences of agents with the government taxing them. The two agents in $G_{t}$ have identical homothetic preferences. There is a single good, and endowments are $\omega_{h}=(1,0, \ldots)$ if $h \in G_{0} \cap G^{1}, \omega_{h}=(3,0, \ldots)$ if $h \in G_{0} \cap G^{2}, \omega_{h}=(0, \ldots, 2,1,0, \ldots)$ if $h \in G^{1} \backslash G_{0}$, and $\omega_{h}=(0, \ldots, 1,3,0, \ldots)$ if $h \in G^{2} \backslash G_{0}$. Preferences are given by:

$$
u_{h}\left(x_{h}^{1}\right)=\log x_{h}^{1} \text { if } h \in G_{0} \text { and } u_{h}\left(x_{h}^{t}, x_{h}^{t+1}\right)=(1 / 2) \log x_{h}^{t}+(1 / 2) \log x_{h}^{t+1} \text { if } h \in G \backslash G_{0} .
$$

Then $p=(1,3 / 4,9 / 16, \ldots)$ supports an efficient equilibrium with no outside assets. The equilibrium allocations satisfy $\left(x_{h}^{t}, x_{h}^{t+1}\right)=(11 / 8,11 / 6)$ for $h \in G^{1} \backslash G_{0}$ and $\left(x_{h}^{t}, x_{h}^{t+1}\right)=(13 / 8,13 / 6)$ for $h \in G^{2} \backslash G_{0}$. Country 1 has a trade deficit in every period, and free trade Pareto-dominates autarky. ${ }^{16}$ The agents in Country 1 lend to their counterparts in Country 2; since the lenders receive interest payments in old age,

${ }^{16}$ The autarkic equilibrium in country 1 is supported by $p=(1,2,4, \ldots)$ and that in country 2 is supported by $p=(1,1 / 3,1 / 9, \ldots)$. 
country 1 runs a trade deficit owing to its surplus on interest income from abroad.

Now consider $\left(\Lambda^{t}\right)_{t=0}^{\infty}$ with $\Lambda^{0,1}=\Lambda^{0,2}=0$, and $\Lambda^{t, 1}=\sum_{s=0}^{t}(3 / 4)^{s}$ and $\Lambda^{t, 2}=-\sum_{s=0}^{t}(3 / 4)^{s}$ for $t \geq 1$. This sequence is generated by the policy $\mu_{h}=\left((3 / 4)^{t}, 0\right)^{\prime}$ if $h \in G^{1} \cap G_{t}$ and $\mu_{h}=\left(0,-(3 / 4)^{t}\right)^{\prime}$ if $h \in G^{2} \cap G_{t}$, with $t \geq 1$. If $q^{0}$ is collinear with $(1,1)^{\prime}$, then $q^{0} \cdot \Lambda^{t}=0$ for all $t$, and $p=(1,3 / 4,9 / 16, .$.$) still supports an$ equilibrium. Further, $e^{2,1}=1$ is the only exchange rate such that $\lim _{t \rightarrow \infty} q^{0} \cdot \Lambda^{t}=0$.

This international generational policy clearly benefits the residents of Country 1 since it allows them to run a larger trade deficit. But, if $q^{0,1}=q^{0,2}<\sqrt{ } 3 / 12$, then the equilibrium allocations Pareto-dominate those in autarky and are in the core of the world economy.

Country 1 in autarky constitutes a Samuelsonian economy, and the coalition consisting of all the agents in $G^{1}$ can achieve the feasible allocation $x_{h}=3 / 2$ for $h \in G^{1} \cap G_{0}$ and $x_{h}=(3 / 2,3 / 2)$ for $h \in G^{1} \backslash G_{0}$. It is possible to show that the agents in $G^{1}$ can block any allocation that entails their running a perpetual trade surplus. On the other hand, Country 2 in autarky is a classical economy, and those agents can form no coalition allowing them to run a perpetual trade deficit. Since international trade Pareto-dominates autarky, the government of Country 2 is willing to increase its trade surplus and accommodate the expansion in Country 1. Finally, note that if Country 2 did not run generational surpluses, then the generational deficits Country 1 would not be consistent with asset market equilibrium because the world economy is in a classical equilibrium!

The second example illustrates the existence of a unique vector of exchange rates in a three-country world. It hinges upon the fact that the fiscal authorities manipulate their stocks of national generational debt in cycles of surpluses and deficits. The cycles are not synchronized, and there is a unique vector of exchange rates insuring the dynamic efficiency of the world economy. The different patterns of adjustment to external deficits are the two common trends determining the exchange rates in the world system.

Example 2: Let $m=3$ and $N_{t}=3$ for all $t \geq 0$, and identify sequences of agents with the authority taxing them. Again, there is a single good per period, and the three agents in $G_{t}$ have the same homothetic preferences given in Example 1. Now endowments are $\omega_{h}=(1,0, \ldots)$ if $h \in G_{0} \cap G^{1}, \omega_{h}=(3 / 2,0, \ldots)$ if $h \in G_{0} \cap\left(G^{2} \cup G^{3}\right), \omega_{h}=(0, \ldots, 2,1,0, \ldots)$ if $h \in G^{1} \backslash G_{0}$, and $\omega_{h}=(0, \ldots, 1 / 2,3 / 2,0, \ldots)$ if $h \in\left(G^{2} \cup G^{3}\right) \backslash G_{0}$.

Again, $p=(1,3 / 4,9 / 16, \ldots)$ supports an efficient equilibrium without assets. Equilibrium allocations satisfy $\left(x_{h}^{t}, x_{h}^{t+1}\right)=(11 / 8,11 / 6)$ for $h \in G^{1} \backslash G_{0}$ and $\left(x_{h}^{t}, x_{h}^{t+1}\right)=(13 / 16,13 / 12)$ for $h \in\left(G^{2} \cup G^{3}\right) \backslash G_{0}$.

Now consider $\left(\Lambda^{t}\right)_{t=0}^{\infty}$ with $\Lambda^{0,1}=\Lambda^{0,2}=\Lambda^{0,3}=0$, and $\Lambda^{t, 1}=\sum_{s=0}^{t}(3 / 4)^{s}$. $[\sin (\pi s / 2)+\cos (\pi s / 2)], \quad \Lambda^{t, 2}=-\sum_{s=0}^{t}(3 / 4)^{s}[(1 / 3) \sin (\pi s / 2)+\cos (\pi s / 2)], \quad$ and $\Lambda^{t, 3}=-\sum_{s=0}^{t}(3 / 4)^{s}[\sin (\pi s / 2)+(1 / 3) \cos (\pi s / 2)]$ for $t \geq 1$. This sequence is generated by the unusual generational policy:

$$
\mu_{h}= \begin{cases}\left((3 / 4)^{t}[\sin (\pi t / 2)+\cos (\pi t / 2), 0,0)^{\prime}\right. & \text { if } h \in G^{1} \cap G_{t} \\ \left(0,-(3 / 4)^{t}[(1 / 3) \sin (\pi t / 2)+\cos (\pi t / 2)], 0\right)^{\prime} & \text { if } h \in G^{2} \cap G_{t} \\ \left(0,0,-(3 / 4)^{t}[\sin (\pi t / 2)+(1 / 3) \cos (\pi t / 2)]\right)^{\prime} & \text { if } h \in G^{3} \cap G_{t}\end{cases}
$$


all with $t \geq 1$. If $q^{0}$ is collinear with $(1,3 / 4,3 / 4)^{\prime}$, then $q^{0} \cdot \Lambda^{t}=0$ for all $t$, and $p=(1,3 / 4,9 / 16, \ldots)$ still supports the equilibrium. Further, $e^{2,1}=e^{3,1}=3 / 4$ and $e^{3,2}=1$ are the only exchange rates such that $\lim _{t \rightarrow \infty} q^{0} \cdot \Lambda^{t}=0 .{ }^{17}$

Again, for sufficiently small $q^{0,1}>0$, the equilibrium allocations Pareto-dominates those in autarky for all three countries. These cyclical deficits and surpluses are in the core of the world economy.

The second example illustrates a compelling interpretation of a common trend. Fiat assets given to Ms. $h$ causes a generational current account deficit for the country where she resides. If the equilibrium is efficient, then this deficit must eventually be "financed" by the accumulation of "foreign exchange reserves" by some other country. A common trend is a pattern that divides the seigniorage from the creation of international asset balances. A unique vector of exchange rates implies a fixed pattern for these trade balances. Let $\mu$ be such that $\left(\Lambda^{t+1, j}-\Lambda^{t, j}\right)=1$; then, if exchange rates are unique, the $m-1$ common trends describe precisely the long-run accumulation of foreign exchange reserves by the $m-1$ other governments. These trends are description of how the specie-flow mechanism ${ }^{18}$ enforces the adjustment necessary to keep the equilibrium allocations in the core of the world economy. A unique exchange rate, then, represents the pattern of absorption of the specie outflow induced by a country's expansion and its concomitant generational current account deficit.

\section{Conclusion}

This paper has shown that there is a relationship between efficiency, exchange rates, and international co-operation in a world with many fiat assets. I emphasized that the generational policy of any one country influences agents everywhere through the effects it has on the evolution of present prices in the world economy. The emphasis on efficiency enabled us focus attention upon a subset of asset prices for the world economy.

Using the Malinvaud criterion and placing a uniform bound on world resources, we showed that the vector of exchange rates is not fully indeterminate. We emphasized that an equilibrium satisfying this criterion may support allocations in the core of the world economy. Hence, there may be an ineluctable element of co-operation inherent in an international system. Indeed, in the examples in the last section, there was a unique vector of exchange rates that supported efficient equilibrium allocations. ${ }^{19}$

I have shown elsewhere [14] that countries need not have balanced trade in an economy with fixed exchange rates. This paper emphasizes that a system of fixed

\footnotetext{
${ }^{17}$ Here I am obviously using that $\sin (\pi t / 2)$ and $\cos (\pi t / 2)$ are orthogonal.

${ }^{18}$ See Ibn Khaldoun [18] for an early discussion of this idea.

19 The ideas in this paper generalize to a wider class of equilibria if one is willing to place assumptions on the curvature of consumers' indifference surfaces in a subset of the commodity space. Then one could prove theorems describing necessary and sufficient conditions for dynamic efficiency in terms of rates of increase of each country's generational debt and a corresponding vector of equilibrium exchange rates. This generalization would include the Samuelsonian cases for the world economy, but it would not much enhance the reader's insight into the nature of international generational policies.
} 
exchange rates can maintain the efficiency of equilibrium allocations as long as countries "agree" on a pattern of generational trade imbalances. Moreover, there is a surprising connection between the number of unit roots in the present value of stocks of national debt and the dimension of the set of exchange rates, a finding having obvious empirical implications. Testing these hypotheses using data from the regime of fixed exchange rates in the last two centuries is an open area of research.

\section{References}

1. Aliprantis, C. D., Burkinshaw, O.: An overlapping generations model core equivalence theorem. J. Econ. Theory 50, 362-380 (1990)

2. Auerbach, A. J., Gokhale, J., Kotlikoff, L. J.: Generational accounts: A meaningful alternative to deficit accounting. In: Bradford, D. (ed.) Tax policy and the economy, Vol. 5. Cambridge: National Bureau of Economic Research and MIT Press 1991

3. Auerbach, A. J., Kotlikoff, L. J.: Dynamic fiscal policy. Cambridge: Cambridge University Press 1987

4. Balasko, Y., Cass, D., Shell, K.: Existence of competitive equilibrium in a general overlapping generations model. J. Econ. Theory 23, 307-322 (1980)

5. Balasko, Y., Shell, K.: The overlapping generations model. I: The case of pure exchange without money. J. Econ. Theory 23, 280-306 (1980)

6. Balasko, Y., Shell, K.: The overlapping generations model. II: The case of pure exchange with money. J. Econ. Theory 24, 112-142 (1981)

7. Balasko, Y., Shell, K.: Lump-sum taxes and transfers: Public debt in the overlapping-generations model, Chapter: 5. In: Essays in honor of Kenneth J. Arrow, Vol. II, Equilibrium analysis: Heller, W. P., Starr, R. M., Starrett, D. A. (eds.) Cambridge University Press: Cambridge 1986

8. Benveniste, L. M.: Pricing optimal distributions to overlapping generations: A corollary to efficiency pricing. Rev. Econ. Stud. LIII, 301-306 (1986)

9. Buiter, W. H.: Time preference and international lending and borrowing in an overlappinggenerations model. J. Polit. Econ. 89, 769-797 (1981)

10. Cass, D.: On capital overaccumulation in the aggregative neoclassical model of economic growth: a complete characterization. J. Econ. Theory 200-223 (1972)

11. Chae, S.: Short-run core equivalence in an overlapping generations model. J. Econ. Theory 43, 170-183 (1987)

12. Chae, S., Esteban, J.: Core equivalence in an overlapping generations model. J. Econ. Theory 59, 417-425 (1993)

13. Esteban, J., Millán, T.: Competitive equilibria and the core of overlapping generations economies. J. Econ. Theory 50, 155-174 (1990)

14. Fisher, E. O’N.: Sustainable balance of trade deficits. J. Monet. Econ. 25, 411-430 (1990)

15. Fisher, E. O'N.: A new way of thinking about the current account. Int. Econ. Rev. 36 in press (1995)

16. Gale, D.: Pure exchange equilibrium of dynamic economic models. J. Econ. Theory 6, 12-36 (1973)

17. Hendricks, K., Judd, K., Kovenock, D.: A note on the core of the overlapping generations model. Econ. Lett. 6, 95-97 (1980)

18. Ibn Khaldoun, The Muqadimmah, Volume II, especially the excerpts in Les Textes Economiques de la Mouqaddima (1375-1379), translated into the French by G. H. Bousquet. Paris: Librairie Marcel Rivière et Compagnie 1961

19. Kareken, J. H., Wallace, N.: On the indeterminacy of the equilibrium exchange rate. Q. J. Econ. XCVI, 207-222 (1981)

20. Kovenock, D.: A second note on the core of the overlapping generations model. Econ. Lett. 14, $101-106(1984)$

21. Malinvaud, E.: Capital accumulation and efficient allocation of resources. Econometrica 21, 233-268 (1953)

22. Mundell, R. A.: International economics. New York Macmillan 1968

23. Stock, J. H., Watson, M. W.: Testing for common trends. J. Am. Statis. Assoc. 83, 1097-1107 (1988) 